\title{
Identidad Gamer. Videojuegos y construcción de sentido en la sociedad contemporánea. D. Muriel. Barcelona: Anaitgames, 2018
}

Ivana Belén Ruiz-Estramil

Universidad del País Vasco UPV/EHU

ivanabelenrues@gmail.com
Ante la propuesta de reseñar este libro, quien suscribe estas líneas no pudo más que pensar en la palabra "reto". "Gamer" era una palabra que había oído, pero que sin duda era muy lejana para una "analfabeta videolúdica" que abría tímidamente la carátula del libro, para adentrarse en páginas que poco a poco demostraban la capacidad del autor, de hacer un libro para un público familiarizado con nombres como Call of Duty, Grand Theft Auto 0 League of Legends, pero también para quien no ha ido más allá del "buscaminas".

La obra destaca principalmente por la capacidad de colocar un tema muy específico como es el de los videojuegos, al alcance de un público más amplio que el propiamente aludido por el consumo de este tipo de ocio. Esta cualidad se hace notable gracias a la apuesta misma de escritura con la que el autor desarrolla su argumento, y es que la metodología de investigación que subyace al escrito muestra un estilo en el que el investigador "se desliza" entre los debates actuales articulados por los propios protagonistas de la investigación, quienes juegan a videojuegos, aunque sea desde un diferente nivel de implicación con los mismos.

Coincido con Luca Carrubba, quien realizó el prólogo de esta obra, al decir que impacta la "forma de introducir conceptos muy densos [...] en un lenguaje ordinario" (р. 9). El trabajo de investigación sociológica se despega aquí de convencionalismos haciendo una apuesta arriesgada pero que da sus frutos. Arriesgada porque el autor establece una relación con el campo en donde partiendo de un análisis devuelve información en forma de artículos que publica en AnaitGames con el fin de abrir un debate con los internautas, teniendo la posibilidad así de volver a conseguir información para su análisis, un "ciclo" que enlaza a la perfección el trabajo teórico y empírico.

Tras el "Experimento Gamer", como el propio autor define a su primer capítulo introductorio en el que se recogen no solo la particularidad y potencialidad del objeto de estudio, sino la manera de desarrollar un proyecto como el que señalaba en el párrafo anterior, el autor se adentra en la categoría de "Hardcore Gamer o Gamer subcultural". Esta categoría es quizá la más extendida en el imaginario colectivo, la primera imagen que se nos aparece en la mente cuando se menciona la palabra "gamer", la de un "jugador totalmente dedicado a la práctica de jugar a videojuegos" (p. 31). El autor nos recuerda que esta categoría, impregnada de dicho imaginario, es "restrictiva y excluyente" (ibid.). Este imaginario que no nació ex nihilo, sino que surge en los ochenta y noventa cuando los videojuegos no eran jugados de forma tan extendida como en la actualidad, contribuyó a formar comunidad entre quienes jugaban a crear una "subcultura", como nos recuerda el autor. La pureza de la categoría fundacional, hace que por extensión el concepto de gamer se relacione con este tipo de práctica en concreto, sin dejar espacio a que otras prácticas de juego no tan habituales quedaran fuera del imaginario de lo gamer.

El hardcore gamer es el gamer prototípico, el "true", verdadero ejemplo de gamer popularizado hasta ser un icono de sí mismo, cumplir con una serie de requisitos. Esa es la imagen construida en torno a lo gamer. No se trata de un "experto en videojuegos" (p. 52), sino en alguien que domina la técnica en alguno de sus juegos. Esta imagen no significa que exista una identidad cerrada, sino que por el contrario contribuye a una pugna por la propia definición de gamer, "no es una identidad 
que está en crisis, es una identidad que nace de la crisis de identidad y, por tanto, permanece en un estado de incertidumbre cuántica" (p. 55), como bien concluye el autor en esta primera aproximación a la identidad gamer.

Un segundo momento se adentra en la ruptura de la figura monolítica del casual gamer, se refiere con ello a la figura del "casual gamer". Se trata esta de una noción que resquebraja la idea de gamer, al no identificarse plenamente con el imaginario popularizado de lo que es ser gamer que como veíamos se correspondía a la noción del hardcore. En este caso el jugador no cumple con los mismos requisitos ni se identifica con ellos como posible fuente de reconocimiento, resaltando una menor "implicación" con el juego, pero también una menor "inversión monetaria" (p. 67). Se presenta, por tanto, como una formula distinta de acercarse al videojuego.

Una tercera posibilidad atiende al videojuego como una cultura, se habla así de un gamer como foodie-connoisseur, buscando distinguirse de las figuras anteriores. Esta definición muestra también una pugna por ser la figura prototípica del gamer, en este caso el gamer es alguien que se abre a otros juegos, que atiende al conjunto, al contexto en el que se plantea el propio juego. Como señala el autor, "gameres, así, una categoría que nos ayuda a pensar una serie de problemáticas identitarias pero que a su vez no tiene poder identitario" (p. 99), es una categoría que sirve para pensar en la identidad, una "lente" con la cual mirarla.

$\mathrm{El}$ autor se detiene en un siguiente punto en lo que llama "(no) gamer cultural-intelectual", para hablar de quien se adentra en profundidad en el mundo del videojuego, sin necesariamente entenderse como gamers, posicionándose en ocasiones como abiertamente contrarios a esa identificación. En ocasiones los videojuegos son el trabajo al que estos sujetos se dedican, su aproximación al videojuego se entiende a menudo como cultural, no tanto en busca de un entretenimiento, sino de un conocimiento.

Lo gamer se convierte en un "acertijo", como hablara el autor en un siguiente momento en el que se detiene en el panorama que las anteriores categorías surgidas alrededor de los videojuegos, donde todo el mundo podía ser entendido como gamer, dado que precisamente el término es referencial, no sin contar con una definición demarcada.

El planteamiento del acertijo gamer resalta la disolución de la propia categoría que llega a ser tautológica "gamer es el que es gamer [...] si te consideras un gamer, entonces eres un gamer" (p. 132), de esta manera, la definición no depende ya del cumplimiento de unos requisitos rígidos sino de un autoreconocimiento. Otra idea fundamental se relaciona con el hecho de que a medida que los propios videojuegos se van popularizando, la práctica de jugarlos se irá también alejando de una característica que pudiera llegar a construir una seña identitaria.

El autor nos recuerda así que "la identidad gamer nace en un momento en el que los propios espacios tradicionales de seguridad de la identidad se desvanecen" (p. 138), siendo de este diagnóstico de donde se desprende la principal característica que visibiliza la potencia del concepto de gamer. El acertijo gamer muestra la encrucijada en la que todo estudio de la identidad se encuentra en un contexto actual, en el que esta no resulta ya tan fácil de definir aquello que construye identidad y lo que no. La idea de gamer, la noción quizá más estereotipada, jugaba un fuerte componente identitario, pero que poco a poco ha visto como el aumento de público que accedía a los videojuegos, introducía también diferentes tipos de relacionarse con ellos. Se convierten así en parte de un paisaje cotidiano de la realidad social, ya no son especiales ni reconocidos como parte de nuestra cultura, instalándose en el imaginario colectivo. En este momento los videojuegos empiezan a perder la capacidad de generar grupo, la identidad gamer "se diluye" (p. 146).

La obra no evita temas controvertidos, al contrario, los analiza con gran capacidad como muestra el abordaje de la cuestión de género y el ámbito de los videojuegos. Para ello, el autor se apoya fundamentalmente en el trabajo que desarrollan dos webs, "Todas Gamers" y "Gaymer.es". Ambos proyectos focalizan su labor en plantear un espacio que no sea hostil a ciertos colectivos que se encuentran discriminados en los espacios hegemónicos. El proyecto de Todas Gamers "persigue educar 0 reeducar a los hombres y sus comportamientos respecto a las mujeres dentro de la comunidad ga- 
mer" (p. 163). La plataforma Gaymer.es es un colectivo que trata la cuestión gamer desde la perspectiva LGTB, Ilenando un hueco informativo que pocas veces abordan otros medios, construyendo de este modo un nuevo espacio social y articulando una reivindicación política, convirtiéndose una herramienta de visibilización en donde se defienden los derechos LGTB (p. 169).

Todo el recorrido de la obra lleva al lector a unas conclusiones en donde a través de tres "paradas" se articula una reflexión final que entrelaza la esfera de actualidad con la capacidad para entender el análisis que el propio libro nos ha dibujado. Se habla así de "el teorema de M. Rajoy", "las formas mínimas de la identidad" y "quiero ser gamer". La ironía y una lectura que sin duda sacará alguna risa, muestra los entresijos que la identidad plantea en una sociedad contemporánea, en donde la identidad gamer funciona como un material analítico perfecto para abordar esa paradoja en la que se inscribe la identidad, cualquiera que sea la forma que esta adquiera.

Las formas "mínimas y evanescentes de la identidad" representan así un paso ineludible que se enmarca en las características fragmentadas en las que actualmente se presenta la identidad, ante lo cual se plantea la posibilidad de entender la identidad como un puzle que conforman un todo que puede modelarse, que se articula de distintas maneras en función del contexto.

Partiendo de la premisa de que "ya que no podemos ser definidos por algo que englobe todo lo que somos, podemos ser definidos por cualquier cosa que nos describa en un momento dado" (p. 203), una persona puede ser clasificada de muchas maneras distintas en función de sus características en un momento determinado, pudiendo cambiar al instante siguiente, siendo por tanto el contexto mismo el que relativiza la fuerza de esas características que posibilitan una clasificación. La identidad gamer se asienta a la perfección en este diagnóstico, y por ello la obra termina con un interrogante que vuelve sobre el reto mismo del propio estudio de la identidad desde la sociología contemporánea, para cuestionarse si "la identidad gamer es construcción de sentido en un contexto social en el que impera la imposibilidad de construir sentido" (p. 206), y ahí precisamente reside toda la potencia de la obra.

Este libro es sin duda un texto donde han participado muchas manos, donde el autor teje la red que las contiene, y en ese ejercicio va plasmando argumentos y reflexiones que dejan la puerta abierta a pensar ya no solo la identidad gamer, sino también la identidad en general. Sus páginas son muy amenas, siendo atrayentes tanto para quienes estén interesados en la sociología de la identidad, como para quienes no pertenezcan al campo de la sociología pero conozcan el ámbito de los videojuegos y tengan interés en conocer el mundo social que se mueve alrededor de ellos. Se trata de una obra que resulta de fácil lectura, sin renunciar por ello al trabajo teórico y analítico, de recomendable lectura tanto para un experto en videojuegos como para un neófito en la materia, cualidad que sobresale en una redacción que nos acerca al mundo de los videojuegos pero también al análisis de la identidad. 
